\title{
Green Propellant Infusion Mission Thruster Performance Testing for Plume Diagnostics
}

\author{
Matthew C. Deans ${ }^{1}$, Brian D. Reed ${ }^{2}$, Lynn A. Arrington ${ }^{3}$ \\ NASA Glenn Research Center, Cleveland, OH 44135 \\ George J. Williams ${ }^{4}$, Jun J. Kojima ${ }^{5}$ \\ Ohio Aerospace Institute, Cleveland, OH 44135 \\ McKenzie I. Kinzbach ${ }^{6}$ \\ University of Cincinnati, Cincinnati, $\mathrm{OH} 45221$ \\ Christopher H. McLean ${ }^{7}$ \\ Ball Aerospace and Technologies Corporation, Boulder, CO 80301
}

\begin{abstract}
The Green Propellant Infusion Mission (GPIM) is sponsored by NASA's Space Technology Mission Directorate (STMD) Technology Demonstration Mission (TDM) office. The goal of GPIM is to advance the technology readiness level of a green propulsion system, specifically, one using the monopropellant, AF-M315E, by demonstrating ground handling, spacecraft processing, and on-orbit operations. One of the risks identified for GPIM is potential contamination of sensitive spacecraft surfaces from the effluents in the plumes of AF-M315E thrusters. NASA Glenn Research Center (GRC) is conducting activities to characterize the effects of AF-M315E plume impingement and deposition. GRC has established individual plume models of the $22-\mathrm{N}$ and $1-\mathrm{N}$ thrusters that will be used on the GPIM spacecraft. The model simulations will be correlated with plume measurement data from Laboratory and Engineering Model 22-N, AF-M315E thrusters. The thrusters are currently being tested in a small rocket, altitude facility at NASA GRC. A suite of diagnostics, including Raman spectroscopy, Rayleigh spectroscopy, and Schlieren imaging are being used to acquire plume measurements of AF-M315E thrusters. Plume data will include temperature, velocity, relative density, and species concentration. The plume measurement data will be compared to the corresponding simulations of the plume model. The GRC effort will establish a data set of AF-M315E plume measurements and a plume model that can be used for future AF-M315E applications.
\end{abstract}

\section{Introduction}

$\mathrm{N}$ ASA's Space Technology Mission Directorate (STMD) has funded the Green Propellant Infusion Mission (GPIM), a technology demonstration mission (TDM) that will demonstrate the operation of a green monopropellant, AF-M315E. The GPIM project intends to fly an operational AF-M315E green propulsion system on a Ball Aerospace-built BCP-100 spacecraft. (Ref. 1) AF-M315E is from a family of monopropellant formulations composed of an ionic salt aqueous solution, which acts as an oxidizer, and one or more fuel elements. These ionic salt monopropellant formulations have been referred to as "green", because they have reduced toxicity hazards compared to hydrazine (the current state-of-art monopropellant), potentially resulting in lower ground handling and transportation costs. (Ref. 2) These green monopropellants typically are formulated to provide higher density and specific impulse than hydrazine.

${ }^{1}$ GPIM Co-Investigator, Aerospace Engineer, Ascent and Thermal Propulsion Branch, 21000 Brookpark Rd, MS 301-2, Member AIAA.

${ }^{2}$ Aerospace Engineer, In-Space Propulsion Systems Branch, 21000 Brookpark Rd. MS 86-8.

${ }^{3}$ Aerospace Engineer, Space Combustion and Materials Branch, 21000 Brookpark Rd. MS 35-6.

${ }^{4}$ Senior Scientist, In-Space Propulsion Systems Branch, 21000 Brookpark Rd. MS 16-1, Associate Fellow AIAA.

${ }^{5}$ Principal Scientist, Combustion Devices Branch, 21000 Brookpark Rd. MS OAI.

${ }^{6}$ Undergraduate Researcher, College of Engineering and Applied Sciences, 2901 Woodside Drive.

${ }^{7}$ GPIM Principal Investigator, Mission Systems Engineering, 1600 Commerce Street, Boulder, CO 80305, Senior

Member AIAA. 
GPIM is led and managed by Ball Aerospace \& Technologies Corp. (Ball), with partners including Aerojet Rocketdyne, the Air Force Research Laboratory (AFRL), NASA's Glenn Research Center (GRC), Kennedy Space Center (KSC), and Goddard Space Flight Center (GSFC). STMD programmatic and technology oversight is provided by the Marshall Space Flight Center (MSFC).

One of the primary goals of the TDM program office is the application of the new technologies demonstrated in these missions into future spacecraft. These TDM projects serve as a means by which to establish spaceflight heritage of technology necessary for acceptance in to more risk adverse missions. GPIM is focused on the infusion of AF-M315E propulsion systems into industry, NASA, and Department of Defense market sectors. As a matter of course during the GPIM program, AF-M315E compatible propulsion system components will be developed, qualified, and flown. On-orbit experiments will also be performed characterizing thruster performance, repeatability, and the ability to perform RCS and delta-V maneuvers required for normal spacecraft operations.

One of the potential concerns with AF-M315E thrusters are the plume impingement impacts. The AF-M315E decomposition products include a high percentage of water, which could condense on solar arrays or optical surfaces. Carbon monoxide, methane, and ammonia have also been identified as contamination concerns. Prior to the activities outlined in this paper, there has not been any significant plume modeling or characterization of AF-M315E thrusters. Proper infusion of this technology is therefore highly dependent on understanding the composition and distribution of AF-M315E thruster plumes and the ability to predict the deposition rates of effluents on spacecraft surfaces.

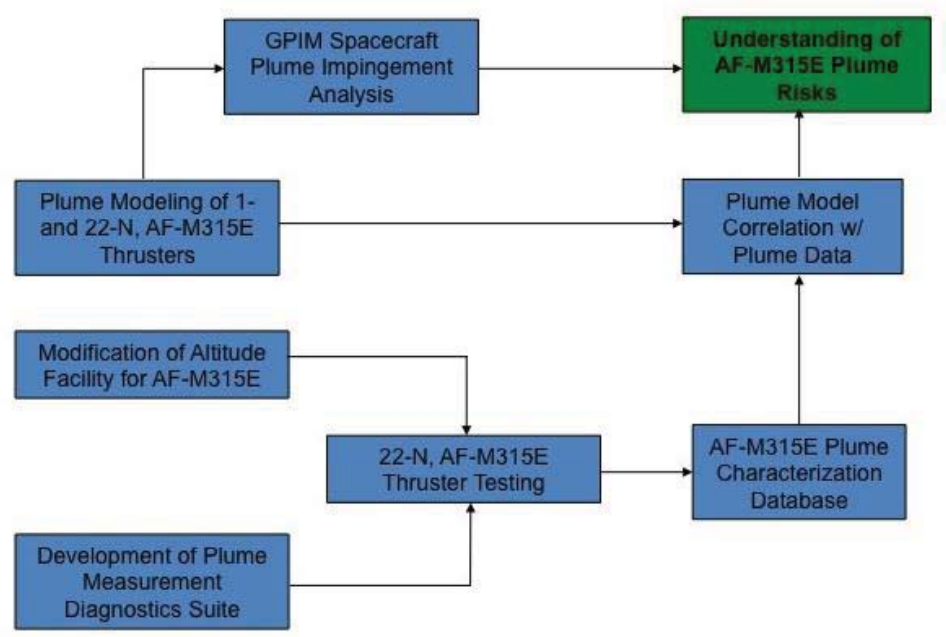

Figure 1. NASA GRC Plume Risk Reduction Activity

GRC will mitigate the AF-M315E plume risk under GPIM through plume modeling and characterization. Plume models of 22-N and 1-N AF-M315E thrusters have been developed using two different numerical simulation methods. The impacts of the AF-M315E thruster plumes on the BCP-100 spacecraft have been assessed by predicting impingement effects and deposition rates onto the spacecraft surfaces. The plume impingement effects on the spacecraft's solar array power generation capability will also be evaluated. Plume measurements will be

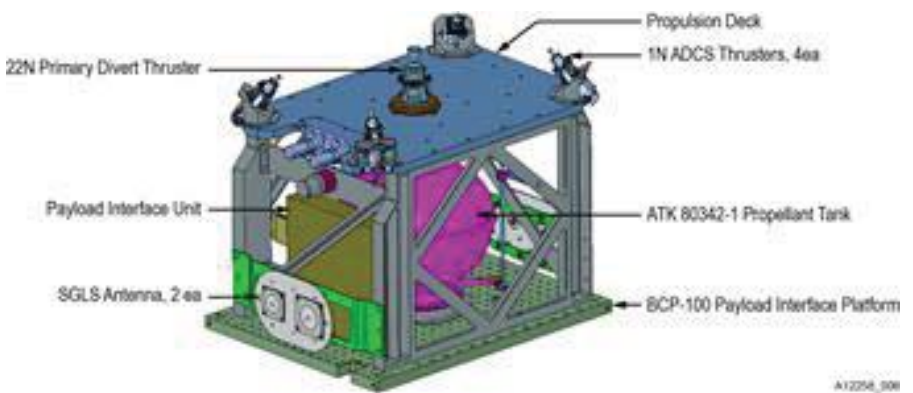

Figure 2. Conceptual Design of AF-M315E Propulsion System ADCS: Attitude Determination and Control SGLS: Space to Ground Link System (Ref. 1) made during hot-fires of two (2) $22-\mathrm{N}$, AF-M315E thrusters. The plume measurements will be compared to the plume model results. If necessary, the plume modeling will be adjusted based on the plume characterization data. The plume risk mitigation effort, then, will result in an assessment of the AFM315E plume impacts on the GPIM spacecraft, a baseline set of AF-M315E plume measurement data, and an AFM315E plume model that can provide plume impingement analysis for future applications. Figure 1 summarizes the GRC plume modeling and characterization activity. 


\section{GPIM Background}

Figure 2 shows the conceptual design of the GPIM propulsion system. The propulsion system will have a single $22-\mathrm{N}$ thruster for delta- $\mathrm{V}$ maneuvers and four (4), 1-N thrusters for attitude control, operating in blow-down mode. The propulsion system will perform typical on-orbit operations representative of spacecraft flight requirements.

The AF-M315E propulsion system will be a payload on the BCP-100 spacecraft. The BCP100 is a spacecraft developed and flown as a technology demonstration platform for the Air Force Space Test Program. The small, modular spacecraft was designed to interface with an Evolved Expendable Launch Vehicle (EELV) Secondary Payload Adapter (ESPA), where it can be launched as a secondary payload. Figure 3 shows the BCP-100 with the GPIM payload after deployment.

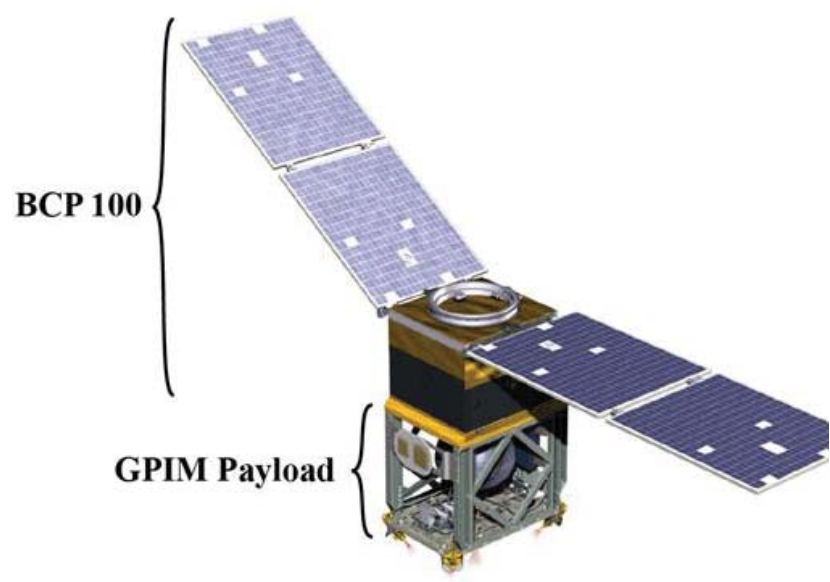

Figure 3. GPIM Payload on the BCP-100 Spacecraft BCP: Ball Configurable Platform

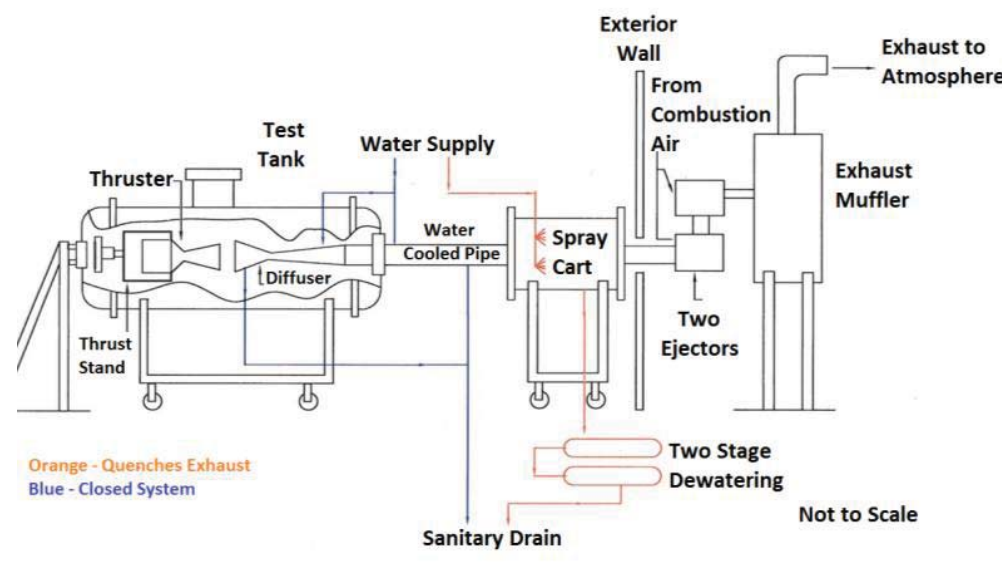

Figure 4. RCL-11 Schematic
III. Thruster Testing Facility

Plume measurements of an AF-M315E thruster will be conducted at GRC's Research Combustion Laboratory - Cell 11 (RCL-11). RCL11 is a small rocket $(<220-\mathrm{N})$, altitude $(36.6 \mathrm{~km})$ facility designed with optical access to incorporate the use of laserbased diagnostics. A simple schematic is shown in Figure 4. The facility uses a six- foot long, three-foot diameter cylindrical vacuum tank. The vacuum tank has four viewports, three located in a plane perpendicular to the thruster axis and the other at a 60-degree angle with the thruster axis with views towards the throat. Thrust is measured

via load cells. Vacuum is achieved by the use of a two-stage ejector system driven by motive air supplied from a central GRC facility. The thruster is fired horizontally into a water-cooled diffuser, which provides an additional pumping effect for the vacuum tank. The water cooling system has a two stage dewatering subsystem to maintain the altitude condition of the vacuum tank throughout operation (Figure 5). RCL-11 has been used to test thrusters for up to 1 hour in duration, with the test duration limited by the thruster rather than the vacuum capability. 


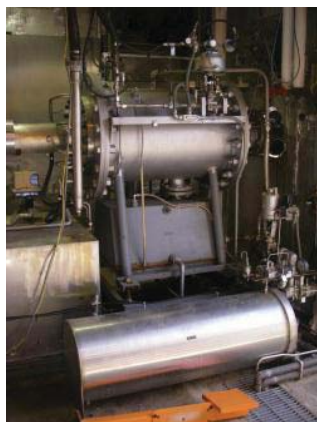

Figure 5. RCL-11 Water Cooling System with Two-Stage Dewatering Subsystem

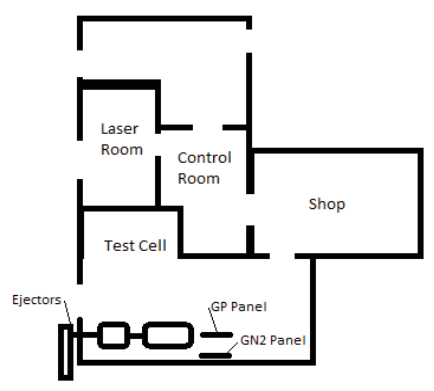

Figure 6. RCL-11 Facility Layout

A simplified diagram of the RCL-11 building is shown in Figure 6. The laser room is able to accommodate different systems used for multiple diagnostics. It has optical access to the test cell and chamber. Like other test cells in the Research Combustion Laboratory, RCL-11 has the ability to be reconfigured for a variety of mono- and bipropellants. A green propellant (GP) flow panel has been installed adjacent to the vacuum chamber.

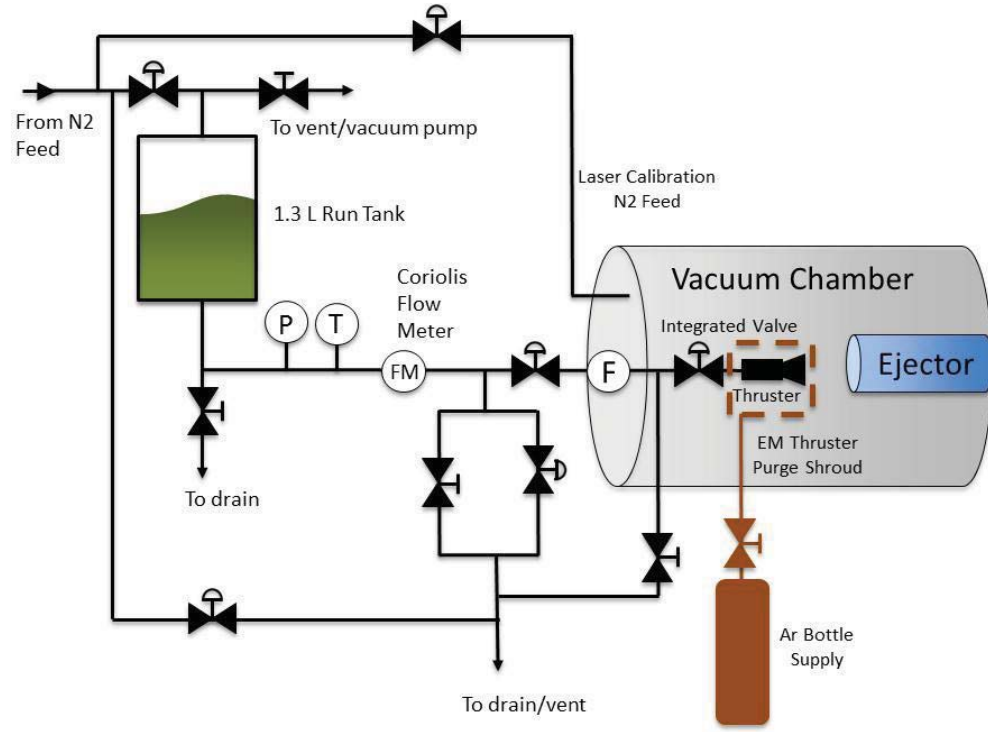

Figure 7. Green Propellant Flow System Diagram

system will operate at discrete controlled pressurization set points. Flow rate is measured by a coriolis flow meter. An optional thruster body purge shroud system has also been installed utilizing argon gas. Additionally, there are separate gaseous feeds to the test chamber for laser calibration with nitrogen.
This panel was assembled to meet GPIM requirements while also allowing for expanded operations. A simplified flow system diagram is shown in Figure 7. Note that not all instrumentation and flow components are shown for clarity. The assembled panel is shown in Figure 8. This panel is adjacent to the vacuum chamber, shown in Figure 9. The system consists of a 0.4 gallon run tank. The maximum allowable working pressure is $1440 \mathrm{psi}(9928 \mathrm{kPa})$ with reliefs set at 1200 psi $(8274 \mathrm{kPa})$. The system is able to be vacuum purged and pressurized with nitrogen. The

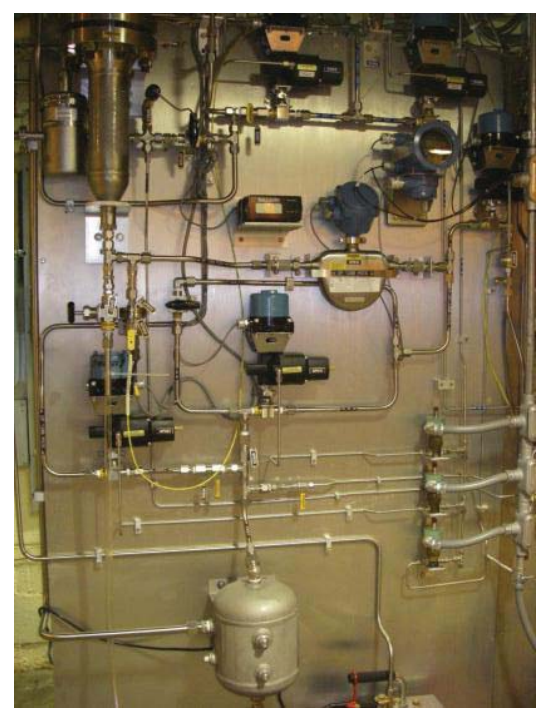

Figure 8. Green Propellant Flow Panel 


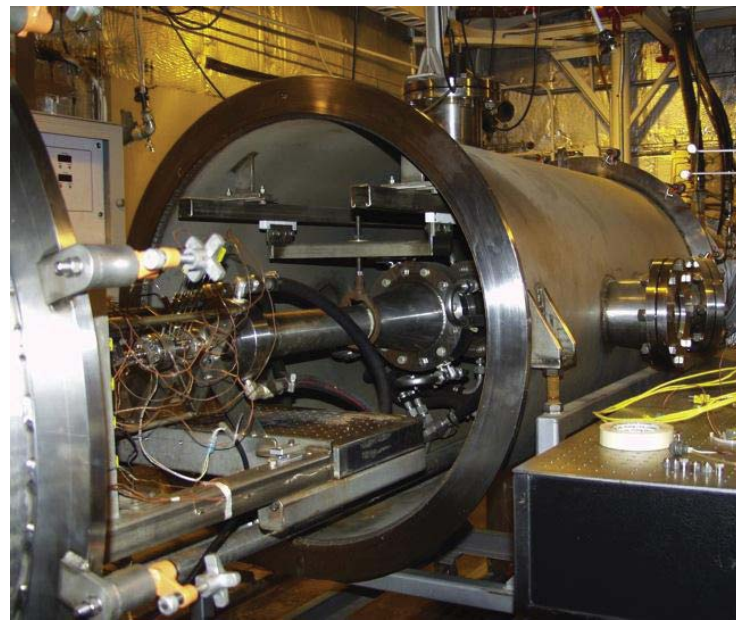

Figure 9. Vacuum Chamber in Open Position
In order to accommodate the testing of AF$\mathrm{M} 315 \mathrm{E}$ the issues of storage, flow system, handling, and disposal have been addressed. Storage of the propellant will be located adjacent to the facility. When defining specifications for the magazine, accommodations for a variety of new propellants other than AF-M315E were also considered. An ATF Type II magazine was selected. The climate control, comprised of a heater and blower, was specified so as to accommodate AF-M315E as well as potential propellants that require more stringent control such as of LMP-103S and other energetic ionic liquids. The magazine, shown in Figure 10, has been sited based on quantity-distance regulations to allow storage of up to $1000 \mathrm{lbs}(453 \mathrm{~kg})$ of a Class 1.3C type explosive.

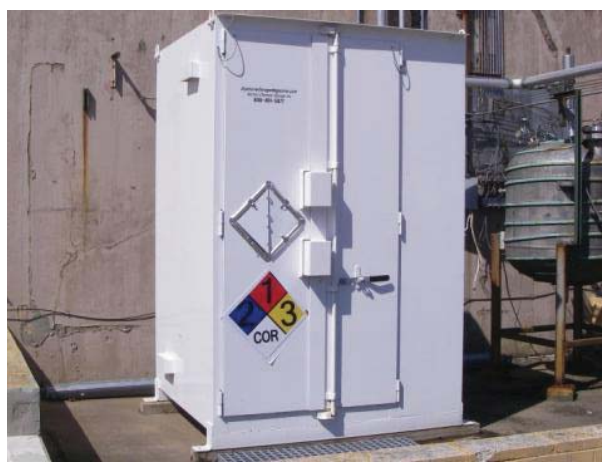

Figure 10. Propellant Storage Magazine

\section{Plume Measurement Diagnostics}

Multiple plume diagnostic approaches are being conducted in order to attempt to provide a wide range of parameters to corroborate testing to the models. To provide a wide range of data, the diagnostic approaches will be carried out throughout thruster catalyst life, through the blowdown pressure range of the GPIM spacecraft, and with firings ranging from approximately 0.5 to 5.0 seconds at various duty cycles. Success of laser diagnostics and discovery of behaviors will drive the test matrix.

Physical probes such as thermocouples or pitot tubes may also be used in the plume to examine the plume, however, the laser and optical diagnostics are the primary intended methods of data collection. Success of those means may preclude testing with physical probes.

Schlieren flow visualization will be used to provide information on the structure and relative density of the plume flow field. (Ref. 3) Schlieren may also provide velocity information via the structure of expansion angles. Not only will this provide a qualitative correspondence to the simulated models, it will aid in defining potential zones of interest for other diagnostic methods.

Rayleigh spectroscopy will be utilized to establish further information on velocity and density. This technique will also be used to analyze the temperature of the plume. (Ref. 4)

Raman spectroscopy is likely the technique of greatest interest to this program due to the unique insights it may provide. Raman yields not only temperature data but is the only technique that will provide species concentration data. (Ref. 4, 5) The anticipated detection threshold should capture the concentrations of the major species and potentially minor species from incomplete combustion. These species will provide insights into the chemistry and degree of combustion. For example, the presence and degree of $\mathrm{CO}$ concentration relative to $\mathrm{CO}_{2}$ may give insights into the combustion efficiency of the thruster. 
Due to the relatively low signal strength predicted, Raman may present the greatest challenge of these diagnostics. Recent advances in camera technology have increased the potential collection sensitivity of the GRC Raman system by 100 to 1000 times and may increase the likelihood of success with detecting signals in low pressure plumes generated by high expansion nozzles; this should provide the ability to detect signals generated in a sub-0.2 psi ( $1.38 \mathrm{kPa})$ plume. The results of this are that multiple point interrogation can be conducted with goals of time resolution of less than 1 second. This should result in both location and time resolved data.

A simplified diagram illustrating the setup of the laser diagnostics in the test cell is shown in Figure 11. The laser will enter through the upper optical access of the chamber and vertically pass through the thruster plume near to the nozzle exit plane. The collection optics are located on the optical table horizontally in line with the side optical access. The system has been designed such that multiple points of interrogation within the plume will be acquired at the same time. One of the interrogation points will target a reference nitrogen stream for calibration.

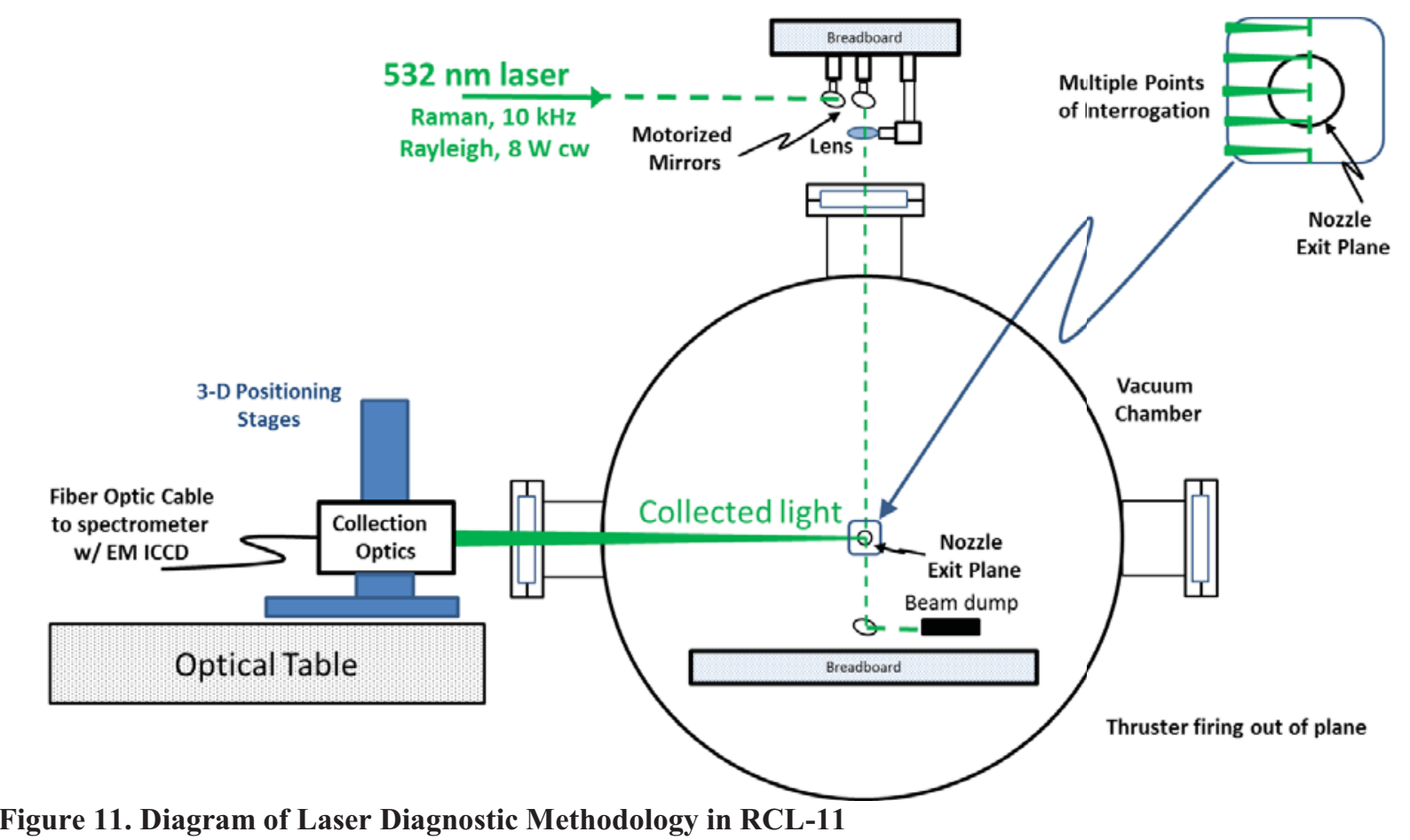

\section{Model Correlation}

The data acquired during the test campaign will be used to anchor plume models that have been developed (Ref. 6). The results of the diagnostics will be used to numerically calculate improved model starting conditions. Simulations with the improvements will be conducted under both experimental and flight conditions. These results may show which approaches or assumptions are best suited to capturing the behavior of this type of thruster and propellant. These models will also confirm which general design guidelines are still applicable. In addition to providing useful simulation tools and design guidance for future flight applications, the results may also provide a more fundamental understanding of the behaviors of these propellants for future research and development.

\section{Thruster Testing}

GPIM testing at GRC will utilize two different AF-M315E 22-N class thrusters. These thrusters were manufactured by Aerojet Rocketdyne - Redmond. The first thruster being tested is a Laboratory Model (LM) thruster; this is essentially a heavyweight and highly instrumented thruster with a relatively small nozzle expansion ratio. Denser gasses emitted from this sized nozzle may yield greater diagnostic signal strength relative to the lower pressure products emitted from a larger nozzle. Additionally, this thruster will provide detailed thermal and pressure 
information of the thruster. Thrust measurement will also be performed as part of the LM thruster firings. Testing with this thruster is currently ongoing at the time of this submission and will continue until July of 2014. NASA GRC is the first NASA center to test these AF-M315E thrusters and perform associated handling, operations, diagnostics, and analyses.

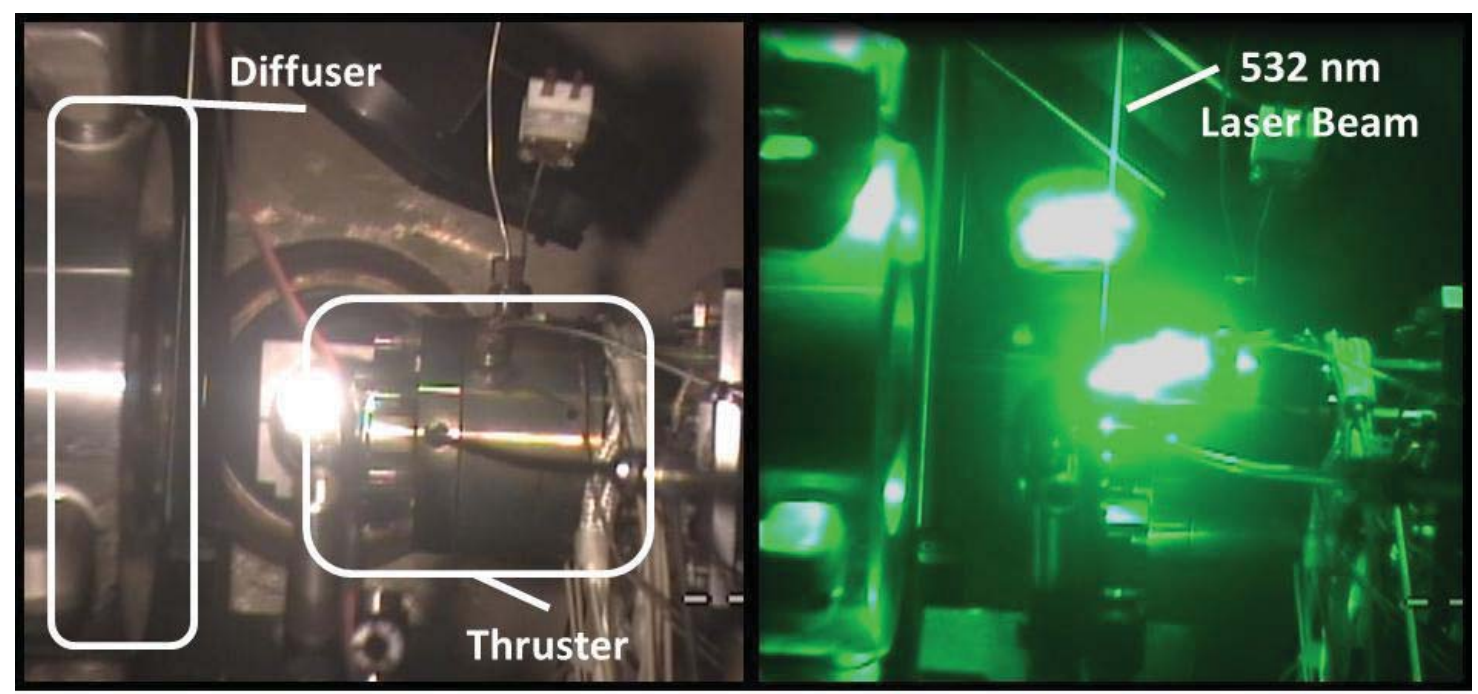

Figure 12. Testing of Laboratory Model Thruster at Altitude

Left: Thruster-Only Firing

Right: Raman Diagnostic Firing

Note: Glowing white spots are reflections; the actual AF-M315E flame is clear

To date, the LM thruster at GRC has performed more than 85 successful firings with an accumulated firing time of over 6.0 minutes. Firings have occurred with duration pulses of up to 8.0 seconds and pulse trains with pulses on the order of $500 \mathrm{~ms}$. The thruster has been tested through much of the GPIM regime with chamber pressures ranging from approximately 100 psia to 300 psia. Both Raman (Figure 12) and Schlieren (Figure 13) diagnostics have begun. Initial Raman diagnostic results appear to be able to resolve signals on scales less than 0.1 seconds providing insights into the behaviors of these thrusters at different points in time within a pulse.

The second thruster to be tested will be an Engineering Model (EM) thruster; this is essentially a flight-like thruster. This thruster will have a larger nozzle expansion ratio. Despite the lower exit pressures associated with the larger nozzle, the improved GRC laser diagnostics may still be able to detect valid signals. Thrust will continue to be measured. Testing with this thruster is currently planned to occur from August to October of 2014. Both thrusters will be modeled and corroborated individually to provide greater insights into plume behavior. Upon completion, detailed results of the testing and diagnostics will be documented and presented in a future release.

\section{Conclusion}

The simulation and experimental work conducted through GPIM at NASA Glenn Research Center are technology risk reduction and infusion aiding tasks so that this advanced propellant may be applied in other missions. This testing, the first firing of these thrusters at a NASA center, are providing valuable information correlating plume simulation models to the experimental work. These validated and anchored models will provide guidance for not only the Green Propellant Infusion Mission but for the future implementation of the AF-M315E green monopropellant in enhancing future spacecraft.

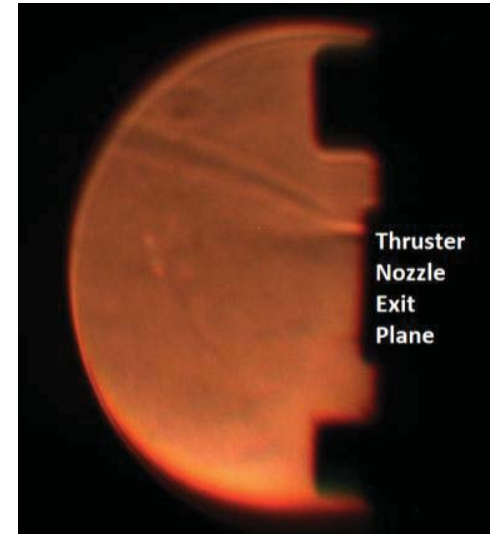

Figure 13: Schlieren Image of Thruster Plume

Note: The two cylindrical shadows above and below the nozzle exit are screw heads 


\section{References}

[1] McLean, C., Hale, M., Deininger, W., Spores, R., Frate, D., Johnson, W., et al. (2013). Green Propellant Infusion Mission Program Overview. 49TH AIAA/ASME/SAE/ASEE Joint Propulsion Conference. San Jose: AIAA 2013-3847.

[2] Marshall, W. M., \& Deans, M. C. (2013). Recommended Figures of Merit for Green Monopropellants. Cleveland: NASA/TM-2013-216560.

[3] Mercer, C., editor, Optical Metrology for Fluids, Combustion and Solids, Kluwer Academic Publishers, Boston, MA 2003.

[4] Eckbreth, A. C., Laser Diagnostics for Combustion Temperature and Species, Abacus Press, Energy and Engineering Science Series Volume 7, Cambridge, MA 1988.

[5] Kojima, J., Fischer, D., \& Nguyen, Q.-V., Subframe Burst Gating for Raman Spectroscopy in Combustion, Optics Letters Vol. 35, Issue 9 (2010) pp. 1323-1325.

[6] Yim, J., Reed, B., \& McLean, C. (2013). Green Propellant Infusion Mission Plume Impingement Analysis. 49TH AIAA/ASME/SAE/ASEE Joint Propulsion Conference. San Jose: AIAA 2013-3850. 